\title{
Itinerários na correspondência entre Oliveira Lima e Fidelino de Figueiredo (1912-1928)
}

\author{
Itinereries on the correspondence between Oliveira Lima and Fidelino \\ de Figueiredo (1912-1928)
}

\author{
Teresa Malatian \\ tmalatian@uol.com.br \\ Professora Titular \\ Universidade Estadual de São Paulo/Franca \\ Av. Eufrásia Monteiro Petraglia, 900 \\ 14409-160 - Franca - SP \\ Brasil
}

\begin{abstract}
Resumo
Este artigo pretende analisar a correspondência trocada por M. de Oliveira Lima e Fidelino de Figueiredo, como parte de sociabilidades intelectuais construídas por meio da Sociedade Portuguesa de Estudos Históricos, entre 1912 e 1928. Os conceitos de geração, itinerário e projeto foram aqui utilizados com base nos aportes de P. Bourdieu e J.F.Sirinelli na análise do campo intelectual em que se inseriram esses autores. Trata-se de um sistema regido por relações específicas, com instâncias particulares de seleção e consagração intelectual. Nesse sentido, considera-se que a autonomia do campo intelectual é relativa, por ser afetado não apenas por relações específicas, mas também pelas pressões políticas, econômicas e sociais que interferem no projeto criador, desde sua proposição até as instâncias de consagração de 10 seu autor. O principal projeto historiográfico analisado foi o das obras D. Pedro e $D$. Miguel e $D$. Miguel no trono, escritas por M. de Oliveira Lima.
\end{abstract}

\section{Palavras-chave}

Sociedade Portuguesa de Estudos Históricos; Correspondência; Intelectuais.

\begin{abstract}
This article intends analyse the correspondence exchanged between by M. de Oliveira Lima and Fidelino de Figueiredo, as part of the intellectual sociabilities build throw the Sociedade Portuguesa de Estudos Históricos, between 1912 and 1928. The concepts of generation, itinerary and project had been used based on the P. Bourdieu and J.F. Sirinelli contributions in the analysis of the intellectual field, where these authors were insert. It signifies a system ruled by specific relations, with particular instances of selection and consecration. In this way, we consider as relative the intellectual field autonomy, it means, affected not only by specific relations, but also by the political, economic and social pressures that interfere on the creative project, since its proposition to the instances of its author consecration. The mainly historiographical project analyzed was the works D. Pedro e D. Miguel, and D.Miguel no trono, written by M. de Oliveira Lima.
\end{abstract}

\section{Keywords}

Sociedade Portuguesa de Estudos Históricos; Correspondence; Intellectuals.

Recebido em: 17/2/2015

Aprovado em: 25/9/2015 
O intervalo de trinta anos de idade não impediu que uma sólida amizade surgisse entre dois intelectuais, o brasileiro, diplomata e historiador Manoel de Oliveira Lima (1858-1928) e Fidelino de Figueiredo, o português, escritor e político (1888-1967). Apenas numa ocasião tiveram a oportunidade de encontrar-se pessoalmente, porém a extensa correspondência construiu entre eles pontes, formatou trocas intelectuais e garantiu a manutenção de uma rede de sociabilidades ativa dos dois lados do Atlântico. ${ }^{1}$

Se houve entre eles contatos anteriores a 1912 não é possível afirmar, pois a primeira carta data desse ano, quando formalmente Oliveira Lima foi comunicado da sua eleição para sócio da Sociedade Portuguesa de Estudos Históricos (SPEH), por indicação de outro historiador, o inglês Edgar Prestage (1869-1951). Pode-se verificar o teor do convite formulado por Fidelino de Figueiredo, secretário da associação, em missiva formal que abria as portas da entidade e da colaboração na Revista de História por ela editada:

Tenho a honra de comunicar a V.Exa que, em sessão de 4 de maio do corrente, foi V. Exa eleito sócio desta Sociedade Portuguesa de Estudos Históricos, por unanimidade, mediante proposta do sr. Edgar Prestage (Lisboa, 5/4/1912).

Terminava a carta com a saudação Saúde e fraternidade, adotada em outubro de 1910, logo após a implantação da República em Portugal. Por se tratar de uma saudação entre republicanos, é significativa do posicionamento da sociedade na época.

Os Estatutos remetidos ao novo sócio esclareciam os objetivos da SPEH e a ambiciosa formatação pretendida:

ativar os estudos históricos, mormente os nacionais; contribuir para que seja melhorado o ensino educativo da história e o seu ensino superior; promover a ampliação do nosso ambiente científico trazendo à discussão os modernos problemas das ciências históricas; concorrer para que se estreitem as relações desse ambiente com as sociedades, academias e altas individualidades científicas estrangeiras (Estatutos, 1911).

Procurava agregar intelectuais não só de Portugal, mas também de outros países, em especial brasileiros, objetivo proclamado em seu Manifesto de $1^{\circ} \mathrm{de}$ abril do ano seguinte, que defendia a salvaguarda dos documentos eclesiásticos ameaçados pela separação entre Igreja e Estado em Portugal, instituída pela República (CATROGA 2002, p. 34). A política de memória nacional sinalizava possível destruição de documentos antes preservados em irmandades, confrarias e arquivos paroquiais diversos, doravante revertidos ao poder laico, juntamente com os bens eclesiásticos móveis e imóveis, que incluíam os respectivos cartórios.

Na recém-fundada república portuguesa, demandas por laicização e outras mudanças destinadas a modernizar a sociedade conservadora marcaram a

\footnotetext{
${ }^{1}$ Resultado do projeto de pesquisa "Correspondência de Oliveira Lima", realizada com apoio da FAPESP. A transcrição das cartas contou com a colaboração de Gabriela Cristina Basso Engler Pinto e Maria Conceição dos Santos.
} 
Constituição de 1911, que estabeleceu o regime democrático parlamentar e o pluripartidarismo em substituição à monarquia constitucional extinta por golpe militar. Logo a efervescência política resultaria em instabilidade governamental, que se estenderia até chegar à ditadura salazarista em 1928.

A essa conjuntura respondeu a SPEH com o direcionamento republicano e laico, embora admitisse membros do clero, minoria perante a grande parcela de professores secundários e universitários, jornalistas, engenheiros, advogados, diplomatas, militares, médicos e arquivistas (CORREIA 2002, p. 52).

\section{Itinerários - A Sociedade Portuguesa de Pesquisa Histórica}

A SPEH nucleou intelectuais conhecidos como "espíritos inconformes" e criticamente posicionados perante os excessos cometidos antes e durante a revolução republicana. Dela "extraíram lições confirmadoras da necessidade de continuar em pacífica evolução um velho passado" (FIGUEIREDO 1960, p. 472). Estiveram presentes nesse posicionamento o regicídio, os atentados de diversa natureza, o anticlericalismo exaltado e violento dos anos iniciais da Primeira República portuguesa.

Embora naquela época não compartilhasse as ideias dos monarquistas liderados por Antônio Sardinha e aglutinados no Integralismo Lusitano, ou seja, distante da defesa da volta da monarquia sob novo formato (tradicionalismo, organicismo e corporativismo), Fidelino conservava pontos de contato com esse grupo por rejeitar o republicanismo radical e pautar-se por uma postura 12 conservadora avessa aos "excessos". A SPEH pôde assim constituir-se em local de articulação política além de atuar num ponto nevrálgico, a elaboração da história nacional e tornar-se instância de consagração e legitimação da produção intelectual.

"Inconforme" era também Oliveira Lima, nessa época em movimento de colisão com o Itamaraty e "convertido" temporariamente ao monarquismo redivivo no Brasil. O convite feito a ele para ingresso no grupo nada mais era que o reconhecimento de sua produção intelectual e, não menos importante, de suas posições independentes no Itamaraty em relação à política panamericanista. Ser chamado a integrar a SPEH significava mais um dos momentos de consagração, ele que já os tivera tantos no Brasil, onde integrava a Academia Brasileira de Letras, o Instituto Histórico e Geográfico Brasileiro, a Academia Pernambucana de Letras e o Instituto Arqueológico e Geográfico de Pernambuco, além das inserções no exterior, entre elas a Royal Society of Literature e a Academia de Ciências de Lisboa.

Verdade que se encontrava num momento crítico da carreira diplomática, à beira da aposentadoria após o período passado desde 1908 como ministro plenipotenciário na Legação do Brasil em Bruxelas. Colaborador em diversos e prestigiosos jornais, precocemente se aposentava após anos de atrito com o barão do Rio Branco. Nesse sentido, manter-se integrado a grupos influentes, manter visibilidade no mundo das letras, fazia a diferença.

Não Ihe foi difícil aceitar o convite da SPEH, mesmo porque já mantinha trocas intelectuais com dois de seus membros fundadores, Edgar Prestage e 
João Lúcio de Azevedo. A carta-convite que acompanhou o comunicado oficial de sua eleição, certamente um texto padrão enviado a todos os contatados com essa finalidade, esclarece mais do que os Estatutos os objetivos da academia: "publicidade, público e discussão crítica" com a intenção de promover os estudos históricos, distanciados do racionalismo do século XVIII, do Romantismo, do Materialismo histórico e do Positivismo evolucionista (Carta circular de adesão).

O hiato no epistolário e o teor das cartas seguintes indicam pequeno espaço aberto inicialmente na vida de Oliveira Lima para a convivência com os intelectuais portugueses na recém-fundada academia. Dois anos se passariam antes que novo contato epistolar se estabelecesse entre ele e Fidelino de Figueiredo, ainda que ambos fossem escritores compulsivos e intensamente dedicados à prática da correspondência.

Os contatos foram retomados em 7 de junho de 1914, às vésperas da Primeira Guerra Mundial, quando movimentavam-se as potências europeias agrupadas nas alianças a um passo da beligerância. Já estavam em andamento trocas de livros entre os dois acadêmicos, com o envio de História da Literatura Clássica de Fidelino a Oliveira Lima. Na reciprocidade, havia a promessa do envio de conferências feitas por ele em Stanford e em outras universidades nos Estados Unidos, embora ainda reticente pela surpresa da descoberta do "autor, em quem vejo há algum tempo - desde que o conheço literariamente um dos melhores cultores da crítica histórica e literária em Portugal" (Londres, 7/6/1912). De fato, apesar de jovem, Fidelino já publicara aos 23 anos de idade considerável produção, inicialmente em ficção, depois na área de história, história da literatura e crítica literária, além de manter como editor a Revista de História, em impressionante capacidade de produção intelectual realizada em paralelo ao ofício de professor de liceu e ao envolvimento na política.

Se eram laços formais ainda, a carta mencionada rompeu a cerimônia com a oferta de hospitalidade por Oliveira Lima, em sua casa de Londres, para onde se mudava em caráter que supunha definitivo. A guerra frustraria esse plano e o levaria ao exílio involuntário no Brasil e em seguida aos Estados Unidos, após um providencial ciclo de conferências na Universidade de Harvard, no ano letivo de 1915-1916. Na teia das linhas das missivas, a amizade intelectual se consolidava e ampliava, perceptível na mudança de tratamento, progressivamente derivado do formal vossa excelência, ilustre consócio, para expressões como amigo, amizade, simpatia. O estreitamento e a intensificação das relações entre eles significaram, além de admiração mútua, fortes laços de solidariedade (BOURDIEU 1968, p. 112).

O primeiro acadêmico a "descobrir" Oliveira Lima havia sido Edgar Prestage. Logo após, João Lúcio de Azevedo (1855-1933) entrou em contato pessoal com ele em 1914, em Londres, e desde então se tornaram correspondentes, com o cultivo de intensas trocas de publicações e comentários reciprocamente (re)conhecedores de seus méritos historiográficos. É sintomático deste tipo de relações que ao Ihe enviar a obra O marquês de Pombal e sua época, João Lúcio solicitou sem constrangimento contrapartida, ou seja a divulgação discretamente sugerida, mas impacientemente aguardada e logo depois 
atendida. Oliveira Lima sem dificuldade acedeu com a publicação de artigo sobre o livro no jornal O Estado de S. Paulo em 1909.

Sequência previsível, prosseguiram as trocas intelectuais com o envio do $D$. João VI no Brasil, publicado por Oliveira Lima em 1908, devidamente registrado por João Lúcio em carta de agradecimento, obsequiosa, elogiosa e modelar das amabilidades entre pares, ao denotar legitimidade e consagração das obras:

Não me enganei no antecipado juízo que formava deste seu valioso trabalho histórico, de erudição e sagacidade crítica, não somente notável pela novidade e abundância dos fatos, como pela interpretação deles e dos caracteres representados. D. João $6^{\circ}$, Carlota Joaquina, o conde de Linhares são personagens a quem se não erro, V. Exa confere na história lugar novo e, quero crer, definitivo. Dos episódios, o da fuga para o Brasil aparece-me transformado, e à luz da sua crítica vem a ser uma ponderada e feliz solução, em vez de um vergonhoso conselho do pânico, como até agora ele tinha sido considerado. O abrir das folhas do 2.0 vol. revela-me novas descobertas da crítica, e quadros descritivos de alto valor, que vou ler com grande interesse (Lisboa, 4/9/1909).

À medida que as dificuldades causadas por sua postura germanófila durante a Primeira Guerra Ihe fecharam as portas do regresso a Londres, Oliveira Lima, residindo provisoriamente no Brasil, procurou fortalecer os laços com os intelectuais portugueses, talvez como uma alternativa para o futuro que se delineava nebuloso, mas também em decorrência da sua inquietude intelectual, que o impulsionava sempre para novos contatos, novas trocas, inserção em academias e associações consagradoras de prestígio, onde letras e política se davam as mãos. Ainda que as cartas tenham sido escassas, nesses anos, trocas de obras, informações e indicações avolumavam-se. Prolíficos, os acadêmicos produziam colaborações em diversos jornais, revistas, conferências logo publicadas em brochuras, revistas ou jornais. Esse é o teor principal das missivas, que permitem traçar itinerários desiguais, mas tangentes. Elas sugerem competição por fecundidade, inserção em espaços de consagração, publicação de obras e comentários sobre elas, convites para conferências, mas além disso houve também ajuda mútua em situações de dificuldade, que expressou muito mais do que os interesses acadêmicos e incluiu relações entre os familiares, ou seja, tornaram-se amizades solidamente construídas à distância e cimentadas por uma única viagem de Oliveira Lima a Portugal.

A cumplicidade entre Oliveira Lima e Fidelino decorria do passado comum, da formação no Curso Superior de Letras de Lisboa, identificação poderosa que inspirava confiança recíproca, pois Fidelino logo no início da amizade epistolar, reconhecia no interlocutor qualidades incontestes de "um filho de minha escola, hoje Faculdade de Letras" (Lisboa, 2/6/1915).Como aponta Bourdieu, existe um peso considerável na "relação que o intelectual mantém necessariamente com a escola e com seu passado escolar" em relação a suas escolhas intelectuais mais inconscientes:

Os homens formados numa certa escola têm em comum um certo 'espírito'. Formados segundo o mesmo modelo, estão predispostos a estabelecer com seus semelhantes uma cumplicidade imediata. O que os indivíduos 
devem à escola é inicialmente toda uma herança de lugares-comuns que não são somente discurso e linguagem comuns, mas também terrenos de encontro e terrenos de acordo, problemas comuns e maneiras comuns de abordar esses problemas comuns (BOURDIEU 1968, p. 140-141).

Em 1907, a propósito do recente falecimento de seu antigo mestre Vasconcelos Abreu, Oliveira Lima rendera homenagem ao Curso Superior de Letras que frequentara entre 1884 e 1888, e que no edifício da Academia de Ciências reuniu mestres destacados em estudos humanísticos da cultura liberal do final do século XIX português. Em seu currículo constavam as disciplinas História universal e nacional, Língua e Literatura sânscrita, védica e clássica, Filologia comparada, Literatura grega, latina e moderna, Filosofia e História universal filosófica (LIMA 1971, p. 239-242).

Entre os professores mais influentes, Oliveira Lima destacou Teófilo Braga, da cadeira de Literatura e divulgador do Positivismo e do Republicanismo em Portugal, a quem reservou o prestigioso lugar de formador de toda uma geração, a que viu a virada do século nesse país. Já Fidelino não guardaria tão boas recordações da Escola Normal Superior em que se transformara o Curso Superior de Letras, onde se licenciara em 1910, pois ainda estudante se antagonizara com Teófilo Braga. Não seguiu os estudos de Literatura para distanciar-se do professor, que neles imperava, para dedicar-se ao curso de Ciências Histórico-Geográficas (AMORA 1989, p. 9). Publicou em 1910, recém-formado, o opúsculo O espírito histórico, onde, entre afirmações metodológicas, atribuiu à História missão educativa pelo conhecimento e preservação da memória, uma missão cívica e política para promover racionalidade no processo político, que deveria afastar-se dos excessos revolucionários, em suma, num caminho de moderação em lugar de revolução e da exaltação jacobina que presidiu a derrubada da monarquia no país (CORREIA 2002, p. 68).

Teófilo Braga o assombrou durante todo o período em análise. Pródigo em comentários desdenhosos, em seus Estudos de Literatura, Fidelino atribuiu ao mestre

a absoluta incapacidade crítica [...],incapacidade aumentada ainda pelas consequências da adoção dum sistema que nunca poderá dar o método da história literária, incapacidade que se ilude com divagações históricas, sociais e prolixidades biográficas e bibliográficas (FIGUEIREDO 1917, p. 155).

Sobre o mestre, porém, não se demoraram as expansões dos correspondentes, no esforço de aplainar arestas, que parecem nunca haver prejudicado sua amizade. Ela era garantida pelo fato de terem lustrado os mesmos bancos escolares e pela formação com as referências positivas de Alexandre Herculano, J.P. de Oliveira Martins e Eça de Queirós.

Seguindo sua maior motivação, Fidelino voltara sua principal obra para a Literatura e ao longo da correspondência estimulou Oliveira Lima a recuperar os estudos literários da formação acadêmica, os quais de fato este nunca abandonou, embora ocupassem posição secundária em sua obra. 
Dele resultaram vários estudos desde o inicial Aspectos da literatura colonial brasileira (1896), até os inúmeros artigos de crítica literária disseminados pela imprensa de diversos países. Seu maior investimento não foi feito porém nesse território e sim na historiografia, onde se consagrou. Por seu lado e em movimento contrário, Fidelino sentia-se atraído para os estudos históricos, que constituem parte de sua obra, e até mesmo dos estudos e propostas que publicou sobre o ensino de História em Portugal. Em Portugal nas guerras europeias (1914) sinalizou que a formação no Curso Superior de Letras de Lisboa preparava seus estudantes tanto para a Literatura como para a História, territórios ainda permeáveis, anterior ao progressivo distanciar entre ambas as áreas. Mesmo com trinta anos de intervalo na formação, o curso garantira aos confrades sólidos conhecimentos compartilhados.

Se Oliveira Lima revelou ao longo da troca de correspondência interesse pelos estudos literários, foi mais em caráter de colecionador de livros, pois não se encontra nela o desenvolvimento de pensamento crítico sobre essas obras. Aprazia-Ihe ter toda a produção portuguesa de literatura e de crítica literária recente para incorporá-la à sua biblioteca, que seria negociada com a Catholic University of America, de Washington, para onde ele também se transferiu após a guerra de 1914-18. Mas durante o período anterior a essa transação que the possibilitou manter a biblioteca íntegra e permanecer como seu curador durante os anos que ali viveu e trabalhou como professor (1921-1928), continuava a ser o bibliófilo que percorria antiquários em busca de edições raras, princeps, para compor sua rica coleção. Fidelino foi seu guia e mentor ao the descortinar a produção literária em Portugal, seja na forma de romances, crítica ou História da literatura. Claro que o fazia dentro de seu próprio círculo de relacionamentos, encadeando os nomes das indicações de autores e obras e ao fazê-lo afirmava mais e mais sua posição dominante na SPEH.

Portanto, é na discussão das obras históricas já elaboradas ou em andamento que se percebe maior empenho de Oliveira Lima em diálogos sobre a melhor forma, o melhor conteúdo, o melhor editor, os problemas com as editoras, a falta de tempo para escrever e sobretudo com a repercussão alcançada em termos de tiragem, edições e resenhas críticas publicadas em revistas e jornais. Promover os amigos, os da mesma roda, era compromisso subentendido mas necessariamente explicitado a cada missiva, como um dever fielmente cumprido e devidamente comprovado pelo envio dos recortes de jornal, separatas e números de revistas. Conhecer e fazer-se conhecido entre os confrades, trocar informações bibliográficas, manter-se sempre atualizado com o movimento editorial, em rede de ajuda mútua, essa era a regra do meio.

Pacotes de livros, separatas, "retalhos" de jornais cruzavam os mares e mesmo com o risco de extravio de correio construíram uma sólida ponte entre os dois amigos, alicerçada pelas cartas. Delas foram preservadas 78 enviadas por Oliveira Lima, que tiveram em contrapartida 90 endereçadas por Fidelino de Figueiredo. De tal modo foi intensa a correspondência que sua leitura sugere Fidelino ter se tornado não apenas um dos principais correspondentes de Oliveira Lima na última fase de sua vida, mas sua amizade, essencial ao 
equilíbrio emocional do historiador-diplomata nos Estados Unidos. Distanciado da política e da diplomacia, vivia com sua pensão de diplomata aposentado, que completava com as aulas ministradas na universidade e a impressionante produção de artigos para os jornais em que colaborava, mediante remuneração, notadamente O Estado de S. Paulo, o Diário de Pernambuco e La Prensa, de Buenos Aires.

Não menos importante e significativa foi a amizade para Fidelino. Quando em 1915 novo golpe militar sacudiu Portugal e levou ao poder o general Pimenta Castro, ele não compartilhou e entusiasmo dos revoltosos, conforme relatou a Oliveira Lima os

acontecimentos desgraçados nesta cidade, que gravemente comprometeram o bom nome e futuro do meu país. A certeza do desgraçado significado destes sucessos - triunfo definitivo da impene demagogia e para sempre a perda de qualquer esperança de ordem e paz - produziu-me um forte abalo moral que me levou à cama por alguns dias. Que veneno maldito é a superstição democrática, com que os velhos nacionalistas ignoram o mundo! (Lisboa, 2/6/1915).

A fragilidade emocional, de par com seu intenso envolvimento na política, haveriam de atormentar Fidelino de Figueiredo ao longo de sua vida. A mesma carta citada traz outra informação relevante sobre esse impacto:

provavelmente terei de interromper todo este grato labor para me constranger escrevendo um opúsculo político, que não pode deixar de ser a condenação absoluta de tudo que em Portugal se tem feito desde 1910, ano em que começou a anarquia. Este opúsculo e o ter me recentemente recusado a cumprir a ordem que me deram, para prelecionar aos alunos em elogio dos crimes de 14, 15 e 16 de maio, são motivos mais que suficientes para me demitirem - o que estou esperando a cada momento.

Envolvido a fundo com o Sidonismo, ${ }^{2}$ Fidelino lamentava na correspondênciaa efervescência dos golpes e contragolpes, assumindo posições cada vez mais conservadoras contra o jacobinismo e a difusão do Bolchevismo. Durante os eventos de 21 de outubro de 1921, que se tornaram conhecidos como Noite Sangrenta e puseram fim à Monarquia do Norte pelo Republicanismo radical, seu nome esteve entre os que deveriam ser presos e talvez assassinados. Escapou por pouco a essa sorte por não se encontrar em casa quando esta foi invadida pelos revoltosos (CORREIA 2002, p. 132).

A política conturbada também afetaria Oliveira Lima durante a Grande Guerra, abalado, perseguido e prejudicado em seu projeto de estabelecer residência na Inglaterra, devido ao seu posicionamento germanófilo nos artigos publicados em O Estado de S. Paulo sob o título "Ecos da guerra". Nas missivas, a menção à guerra apenas aflorava o tema, incidindo sobre o seu caráter devastador e principalmente sobre a censura que vigorava na correspondência. Esperava "tempos de liberdade, se é que a liberdade ainda volta ao mundo, do 
que duvido. Creio que desta feita ela bateu definitivamente as asas. São muitos a assustá-la e a querer-Ihe mal" (Londres, 18/9/1915). Por seu lado, Fidelino concordava com a necessidade de igual cautela ao tratar da política, pois as cartas eram invariavelmente abertas pela censura e ele se lamentava "porque guerras sacrificam nos altares dessa deusa caprichosa, a verdade. A censura impede-me de expor fatos" (Lisboa, 22/4/1917). Confidências quase cifradas aparecem nas cartas a sinalizar com sutileza o não dito sobre a guerra e a situação política convulsionada em Portugal.

\title{
Projetos historiográficos partilhados - D. Pedro e D. Miguel
}

Em 1923, realizou-se afinal a viagem a Portugal que Oliveira Lima vinha planejando desde a saída da Inglaterra em 1915. Seria a retomada das suas origens, iniciada com o tratamento médico em 1922 na Alemanha. De Frankfurt, acabou por decidir-se a rever o país de origem de sua família, onde passara a segunda infância, a juventude e o tempo em que ocupou seu primeiro posto no serviço diplomático, como secretário da legação brasileira em Lisboa. Havia terminado mais uma obra, O movimento da Independência, publicado no bojo das comemorações do centenário do Sete de Setembro e se apresentava uma excelente ocasião para divulgar esta obra, contanto com a rede de sociabilidades que vinha construindo há tempos, conforme expressou a Fidelino em carta de 24/3/1921, escrita em Washington:

\begin{abstract}
Assim que puder e antes que me faça muito velho, irei passar uma temporada em Portugal, de que tenho tantas saudades. Sei que infelizmente o Portugal de hoje não é o que eu conheci, mas assim mesmo Ihe quero muito. Aí passei minha infância e minha mocidade. São coisas que nunca se esquecem. Aí jazem meus pais.
\end{abstract}

No ano seguinte, "arribei", dizia ele ao amigo e se preparava para a viagem. Com diplomacia, afagava o sentimento patriótico de Fidelino: Portugal "é a pátria da minha inteligência e posso portanto dizer do meu coração" (Frankfurt, 27/12/1922).

A decisão estava tomada, impulsionada pelos arranjos de bastidores para proferir conferências, promover suas obras, enfim, uma viagem que não seria apenas de turismo. O intercâmbio de obras se intensificava em direção aos confrades e a tudo Fidelino, encantado, acedia. O périplo de seis meses teve início em abril de 1923: Lisboa, Sintra, Bussaco, Porto, Vila do Conde, Ajuda, Aveiro, Coimbra, Viana do Castelo. Mas os ganhos foram muito além. O bombardeio na imprensa foi feito por Fidelino, em jornais portugueses, e pelo próprio Oliveira Lima, em La Prensa de Buenos Aires, e no Jornal do Brasil, para onde enviou a cobertura da viagem com artigos sobre "impressões portuguesas". Ali o homem doente e fatigado ressuscitou e entrou em atividade febril de contatos, visitas, escrita de artigos e cartas, troca de livros e projetos editoriais.

No bojo das comemorações do centenário da Independência do Brasil, inaugurou a cátedra de Estudos Brasileiros na Faculdade de Letras de Lisboa em 9 de junho, com 4 conferências de grande repercussão, certamente orquestrada 
por Fidelino. Foram reunidas no volume Aspectos da história e da cultura no Brasil, publicado no ano seguinte em Portugal, com a intermediação de Fidelino junto ao editor Teixeira. O ponto alto do evento foi sem dúvida a presença de seu antigo mestre Teófilo Braga, que legitimou sua consagração.

Infelizmente não restaram registros do episódio na correspondência, mas as memórias escritas logo após a viagem revelam os meandros da indicação para as conferências, ao correr da pena afiada que não temia, como sempre, consequências de sua liberdade de escrita e se sentia ainda mais segura porque as memórias só viriam a público postumamente. A indicação do conferencista para a inauguração da cadeira era atributo da Academia Brasileira de Letras, da qual Oliveira Lima, embora membro fundador, se afastara por indisposição com o regimento que instituíra a concessão de jetons pelo comparecimento às suas sessões. A passagem embora um tanto longa é digna de ser reproduzida por exemplar do estilo cáustico de Oliveira Lima, especialmente em seus momentos de fúria. Nela fica evidente como sabia administrar a própria consagração:

Por uma deferência para com a Academia Brasileira, foi a esta confiada a escolha do professor e ela decidiu que a seleção se faria fora de suas fileiras, para que não pudessem surgir rivalidades; de fato, para me não caber essa honra, a qual na verdade devia pertencer-me, não por qualquer superioridade de inteligência, mas por um concurso de circunstâncias porque era um antigo aluno da Faculdade de Lisboa; porque os assuntos históricos e literários eram o meu campo de trabalho; porque acabava de aposentar-me e tinha todo o tempo de meu; porque sem ser rico, tinha o bastante para ajudar a magra retribuição do Governo português aos seus professores; finalmente porque me especializara, por assim dizer, tendo feito cursos na Sorbonne e na Universidade de Stanford [leia-se ministrado cursos] e achando-me justamente convidado para inaugurar na Universidade de Harvard a cadeira novamente criada de História e Economia da América Latina. Não podendo ser tachado de imbecil, pois que era acadêmico, reunia assim os requisitos necessários. Creio mesmo que com uma lanterna se não encontraria melhor na caverna mágica em que a herança do livreiro Alves transformou depois a Academia (LIMA 1986, p. 25).

O azedume vinha do fato de ter sido inicialmente preterido por Miguel Calmon, em seguida por Coelho Neto, ambos desistentes. Em suas Memórias, Oliveira Lima deixou registrada sua versão do episódio:

Foi designado o Sr. Miguel Calmon, mas os estudantes de Lisboa ficaram privados das suas interessantíssimas - como seguramente seriam - lições de economia porque ele nunca se resolvera a cumprir o encargo. Voltou-se então aos hors concours e foi convidado pelos seus colegas o sr. Coelho Neto, a quem estava reservado um entusiástico acolhimento e que possui eloquência imaginativa bastante para arrastar estudantes e professores: apareceram porém dificuldades pecuniárias, fazendo o Sr. Coelho Neto valer as despesas de representação a que seria forçado e para as quais considerava insuficiente o subsídio estipulado pelo governo brasileiro. Sete anos se passaram de vacas magras e na congregação, quando se tratava da cadeira brasileira, uns galhofavam e outros se irritavam com a falta de consideração dos nomeados, quando eu cheguei, convalescente de grave enfermidade, a Lisboa, vindo do Norte (LIMA 1986, p. 26-27). 
Afinal o encargo veio para si, passados sete anos do projeto inicial. Aceitou-o com a condição altaneira de não receber estipêndio e de não necessitar da chancela da Academia Brasileira de Letras, afinal consultada "por formalidade". Em desdobramento atendeu a um convite da Universidade de Coimbra, onde proferiu também conferência. Ali era diretor da Faculdade de Letras Eugênio de Castro, seu antigo colega no curso de Superior de Letras.

No itinerário de estreitamento dos laços com intelectuais portugueses, Oliveira Lima, que já era sócio correspondente da Academia de Ciências de Lisboa, ali foi também recebido em sessão presidida por Júlio Dantas, com a presença de Fidelino e João Lúcio. Concretizava-se a acalentada convivência do trio, acompanhada por surpreendente intensificação da correspondência escrita, num extravasar de entusiasmo e emoções. A eles se agregou Antônio Sardinha (1887-1925), monarquista e ideólogo do Integralismo Lusitano. Da epopeia resultou a proposta encaminhada pela direção da Faculdade de Letras ao ministro da Instrução Pública para que fosse concedida a Oliveira Lima a grã-cruz da ordem de S.Tiago da Espada. Seria o ápice da consagração, porém ele acabaria pondo a perder a boa vontade dos portugueses ao emitir, com escasso tato diplomático, juízos descuidados em artigos para La Prensa, criticando a higiene da cidade de Lisboa e a situação política instável do país. Rompia assim com as regras da cordialidade do campo, no que obrigou Fidelino a intermediar - sem êxito - a reconciliação por estar em jogo também o seu prestígio pessoal e o da SPEH.

20 Então ganhou impulso o esforço conjunto pela conclusão do $D$. Pedro e D. Miguel. A escrita desta obra ocupava Oliveira Lima desde 1915, quando residia em Londres, e esteve presente com destaque na correspondência dos anos 1924-27. Projetava escrever uma obra "do ponto de vista brasileiro" em continuação ao $D$. João VI para tratar das relações conflituosas entre D. Pedro I e seu irmão D. Miguel na sucessão portuguesa. O percurso da obra, da escrita até a entrega ao público, é modelar das relações de sociabilidade intelectual estabelecidas mediante a SPEH e do papel nela desempenhado por Fidelino. Nesse sentido o epistolário é especialmente rico ao revelar meandros desconhecidos sobre o funcionamento da rede.

Fidelino participou com entusiasmo da elaboração da obra, intermediando a aquisição de bibliografia. Sem cerimônias e com o aval da posição que ocupava na SPEH, animou-se a opinar sobre a organização em capítulos e volumes, títulos, edição e divulgação em Portugal. Foi uma surpreendente parceria por revelar as complexas relações de dominação/subordinação na SPEH, nas quais Fidelino colocou-se como crítico autorizado e aceito por Oliveira Lima como árbitro da legitimidade e consagração da obra naquele país.

A obra tomou impulso, mas com problemas de saúde e acúmulo de trabalho, Oliveira Lima encontrava dificuldades para finalizar o primeiro volume, que tratava do período de 1826 a 1828, com o aproveitamento de fontes reunidas em pesquisas anteriores nos arquivos de Londres (British Record Office e Foreign Office) e Washington. Não há indícios de terem sido feitas novas consultas a arquivos diplomáticos e mesmo quando se apresentou a oportunidade, durante 
a viagem a Portugal. No entanto, obteve de A. Sardinha indicação bibliográfica: tratava-se de Dom Miguel I Konig von Portugal sein leben und sein Regierung, de Artur Herchen (Elvas, 25/10/1923).

Por razões desconhecidas, havia escrito boa parte, se não a totalidade do livro em francês e planejava publicá-lo em Paris em 2 volumes: La sucéssion portugaise (1826-1828) e L'Empire et le Roi (1828-31), fechando a periodização na "fase militar" da sucessão do trono português, modalidade para a qual, confessava, não possuía "nem gosto, nem competência" (Fernbrook, 16/8/1924). Em 1925, estando a obra pronta e à espera de editor, começaram as trocas de opiniões sobre o título a ser-Ihe dado. Fidelino considerava "A sucessão portuguesa" título "pálido e de pouco augúrio comercial". Aconselhava o autor a "falar de D.Miguel - que é na gente nova objeto de grande interesse". Sugeria como título "D. Pedro e D. Miguel (1826-1834)", bem como a divisão da obra em 2 partes: "A querela da sucessão" e " Reinado de D. Miguel" (Lisboa, 6/1/1925). Em todos os diálogos, a incerteza da periodização prevalecia e indicava problemas na composição da obra, talvez causados pelo enviesamento do enfoque analítico, que incidia sobre o Brasil e não sobre Portugal.

Escrevia com um olho no texto e outro no horizonte em busca de editor para o volume já concluído. Falhado o plano de publicação na França, teve início um movimento em direção a Portugal. As conversas triangulares moviam-se ao sabor da caprichosa indecisão de Oliveira Lima sobre o formato do livro e a busca de editor. A custo ele rendeu-se aos amigos empenhados em dar-Ihe propaganda e enviou-Ihes a relação dos capítulos compostos, pedindo-lhes sugestões:

Assim, com 2 amarras, é natural que o barco flutue e que um dos editores o faça navegar. Mandei dizer ao J. Lúcio que traduziria o livro para o português (isto naturalmente levará alguns meses) se fosse mais viável a publicação. Talvez seja melhor. Se fosse em inglês, o A. de Campos diria que já estou tão americano que nem mais sei o português. Idiota! (Washington, 3/10/1924).

Mas o projeto se arrastava e o segundo volume, a ser intitulado "A realeza de D. Miguel", foi postergado em benefício da tradução do tomo já concluído para o português. Enquanto os amigos movimentavam-se à procura de editor em Portugal, Oliveira Lima entrou em negociação com a editora brasileira Weiszflog \& Irmãos, (Melhoramentos), que já havia editado a História da Civilização e lhe propôs pagar o mesmo valor do Movimento da Independência, ou seja, 3 contos brasileiros. Sem dúvida a edição em Portugal facilitaria sua divulgação na rede de sociabilidade criada na SPEH, mas naufragado o plano, os manuscritos do volume, intitulado conforme sugestão de Fidelino, Dom Pedro e Dom Miguel - $A$ Querela da Sucessão (1826-1828), foram editados em São Paulo. Após tantas démarches, o livro estampou os agradecimentos em dedicatória aos amigos:

À memória de Antônio Sardinha, tão leal, tão animoso, tão vibrante, e a J. Lúcio de Azevedo, o historiador insigne, e Fidelino de Figueiredo, o crítico eminente, os três amigos que, após trinta anos de minha ausência da terra, me deram com sua gratíssima convivência a impressão do Portugal 
da minha mocidade de que eu conservava a saudade, ofereço este estudo ditado pela isenção histórica.

Seria sua última obra publicada em vida.

Acatara sugestão de Fidelino de agrupar em blocos os 42 capítulos curtos que havia escrito e esperava concluir o segundo volume no inverno seguinte, mas como sempre, usava sua enorme capacidade de escrever diversas obras, simultaneamente. Desta feita, estavam em andamento O Império Brasileiro, além das Memórias, mas sua saúde frágil declinava mais e mais, afetando o ritmo de trabalho

Em maio de 1926 Fidelino solicitou as provas da edição para divulgá-las em Portugal antes do lançamento do livro no mercado. Logo Oliveira Lima recebeu duas transcrições de capítulos em jornais portugueses: o Correio da Manhã e o Diário de Lisboa. Fiel às redes de sociabilidade e de amizade, Fidelino orquestrou a divulgação em Portugal e propôs trechos inéditos do livro a revistas e à imprensa, estratégia de propaganda para despertar maior interesse pela obra no público português e, por que não, assim remediar a ausência de editoras portuguesas que referendassem a obra. Organizou uma lista de divulgação entre seus contatos, que compunham a rede de sociabilidades ampliadas. Uma das cartas é especialmente preciosa por conter o traçado do plano. A estratégia de publicar o livro fatiado em capítulos denota a inserção de Fidelino na cultura portuguesa de sua época e nos meios de comunicação, além de sua capacidade

22 de iniciativa e articulação na área, com intensa colaboração na imprensa portuguesa e estrangeira (dela resultaram os volumes Epicurismos e Torre de Babel). O plano meticulosamente traçou a lista de periódicos e escritores que atenderiam à divulgação:

Desta magnífica e novíssima obra mandei capítulos aos jornais. Já começaram a sair e mandei-Ihe alguns; os outros irão também [...].

O Imperador rei e suas dificuldades sul-americanas; As complicações espanholas; A tutela inglesa em perigo e o vento de Espanha; (estes 3 para El Consultor bibliográfico dirigido por D.Carlos Pereira - à escolha);0 efeito da carta - Nação Portuguesa (Manoel Múrias); A outorga da carta Nação realista, Ernesto Gonçalves - "publicado"; A aclamação da nação e o repúdio das potências - Diário de Lisboa, Joaquim Mauro/Manso- publicado; O Papel da Inglaterra - Diário da Tarde, Luís Debonet; O Duque de Bragança - Época, Correa Marques; Saldanha e Palmela3- Correio da Manhã, Lobo Vaz -publicado; Mais 2 outros para a Ação Realista (revista, não jornal homônimo) (Lisboa, 25/6/1925).

Como se pode observar, não está alheio a esse empenho de Fidelino seu comprometimento com o campo político monarquista que se interessava pelo tema da realeza avivado por A. Sardinha com o prefácio ao livro do visconde de Santarém republicado em $1924 .{ }^{4}$ Nele Sardinha opôs ao Liberalismo a monarquia tradicional orgânica e de certa forma reabilitou a atuação de D. Miguel no

\footnotetext{
${ }^{3} \mathrm{~A}$ menção correta é Palmela e Saldanha.

4 Trata-se da segunda edição da obra escrita em 1824, Memórias e alguns documentos para a história e teoria das Cortes Gerais.
} 
contexto da movimentação política monarquista do Integralismo lusitano, da qual Fidelino também participava, como editor da revista Portugália.

Sua opinião inicial foi favorável à obra, mas não tão entusiasta quanto se poderia supor: "De fato é novo no sentido de ser baseado sobre documentos", dizia em avaliação um tanto decepcionada e insistente na necessidade de completá-la com o segundo volume (Lisboa, 12/7/1926). O resultado final do livro do ponto de vista material também não agradara a ele nem ao autor: "O papel empregado foi delgado demais, porque reduziu muito o volume. Assim poderia ter saído toda a matéria num só tomo. Mas não estava escrito o $2^{\circ}$ volume, bem sei" (Lisboa, 18/1/1927), dizia Fidelino. O autor, estoicamente se desculpava e justificava: "não há meio de discutir com os editores. Fazem sempre como querem". Exasperado com o resultado, Fidelino extravasava seu descontentamento pois a expectativa de divulgar o protagonismo de D. Miguel fora frustrada:

O editor esqueceu-se de declarar na capa tratar-se do $1^{\circ}$ volume apenas. Quem vê supõe ser a obra completa um só volume. Valeria a pena adverti-lo para que se não note a falta de matéria ...que está no $2^{\circ}$ volume. A composição está muito apertada e as gravuras estão muito abaixo do texto. Este volume é muito novo, mas o $2^{\circ}$ deve ser mais palpitante, porque trata já de D. Miguel no trono. Aqui a rapaziada arde por o ler, a esse $2^{\circ}$ volume (Lisboa, 25/3/1927).

Sua situação dominante no campo intelectual se revela no tom crescentemente impositivo impresso por ele em suas admoestações a respeito do $D$. Pedro e D. Miguel, que surpreendem pelo azedume e pelo caráter controlador e fiscalizador dos problemas com a edição, pachorrentamente relevados com bonomia por Oliveira Lima, raposa velha e velho lobo do mar habituado aos percalços com os editores.

Mas pode-se também pensar em outra explicação: o livro não tratava com simpatia nem Portugal nem os envolvidos na disputa pelo trono português. Como afirmou Vicente Licínio Cardoso, em crítica publicada em 1927, o livro

não traz nenhuma simpatia pelas figuras, cujos gestos e palavras foram documentadamente estudadas. O livro caracteriza a decomposição a que chegara Portugal, sofrendo influências externas perigosas, ora da Inglaterra, ao da Espanha, ora do próprio Brasil, em contraste com tudo quanto seria de acreditar depois dos acontecimentos que levaram Pedro I ao trono brasileiro tornado independente do trono português.

Há, por assim dizer, nos bastidores áulicos, um verdadeiro regime de opereta, que define uma época histórica paupérrima de qualquer lance de beleza (CARDOSO 1937, p. 187).

Outra carta preciosa revela a rede de sociabilidades ampliada da SPEH, à qual foram enviados exemplares que Oliveira Lima destinara à divulgação naquele país: p. e c.el Ferreira Lima, Queirós Veloso, João Lúcio de Azevedo, Manuel Murias, Aires Ornelas, Viúva de Antônio Sardinha (falecido em 1925), Academia de Ciências, Rodrigues Carvalheiro, Fortunato de Almeida, D.Tomás Vilhena, Hipólito Raposo, D.Carlos Pereira, A Voz , Martinho Nobre de Melo, o 
rei D. Manuel II, Ernesto Gonçalves, Antônio Viana. Seguiu-se aqui a ordem em que foram arrolados na carta de 25/3/1927.

Oliveira Lima completou a lista com os nomes do professor Mendes Corrêa, do Porto, do Visconde de Santarém e de Alfredo Pimenta. Recortes do El Debate de Madri e do Correio da Manhã de Lisboa enviados ao autor documentaram o sucesso da divulgação da obra antes de seu lançamento no Brasil.

Não se pode deixar de mencionar que durante o período de sua primeira gestão à frente da Biblioteca Nacional Fidelino havia sido chefe de gabinete do ministro da Instrução Pública do governo de Sidônio Pais. Mesmo com o revés do final da República Nova em 1919, mantinha contatos importantes e inserções privilegiadas no cenário político e intelectual de Portugal. Em 1927, foi novamente nomeado, em substituição a Jaime Cortesão, durante o governo ditatorial. Deve-se a essa experiência o caráter meticuloso, organizador e conhecedor dos meandros da divulgação de livros o cuidado com que ele tratou a divulgação da obra e mais ainda, da edição, póstuma do segundo volume em 1933, D. Miguel no trono (1828-1933), com seu prefácio. Fechava-se assim o périplo da produção do livro.

À medida que conhecia melhor a obra de Oliveira Lima, Fidelino entusiasmava-se e estimulava o amigo a reunir seus estudos históricos dispersos em revistas e jornais em um único volume aliás repetindo a sua própria estratégia de publicar e republicar obras, reunindo-as sob diferentes títulos. Em 1926 chegou mesmo a elaborar uma proposta de "Memória sobre o descobrimento do Brasil e primeiras negociações" onde seriam reunidos artigos já publicados e 24 que considerava mais significativos: Elogio de Francisco Adolfo de Varnhagen, 0 padre Manuel de Moraes, José Bonifácio, Gustave Beyer, Le Brésil, ses limites, ses voies de pénétration, L'évolution de Rio de Janeiro, La langue portugaise: la Littérature Brésilienne, La conquête du Brésil, O Brasil e os estrangeiros. O empreendimento seria simples:

Os em francês não precisam de ser traduzidos porque o público hispano-americano compreende o francês talvez melhor que o português. Esses estudos têm permanente interesse histórico e não são acessíveis no mercado. O trabalho não é grande: reunir uma coleção, antepor-lhe um pequeno prefácio, juntar notas de atualização, um índice e pronto. Mesmo as provas podem ser vistas por mim, que estou mais próximo. Pense nisto e ouça a opinião da exma. D.Flora (Lisboa, 24/5/1926).

Aconselhava a edição pelo editorial Virtus, de Barcelona, na coleção Biblioteca Histórica Ibero-americana, onde parecia ter entrada, mas o projeto, afinal, nunca foi executado.

Enquanto isso, Fidelino envolvia-se cada vez mais na política portuguesa e se aproximava do campo monarquista, sofrendo as consequências dessa opção, que já lhe custara aborrecimentos em 1919, durante a Noite Sangrenta, quando triunfou o republicanismo radical. De crise em crise, Fidelino não conseguia manter-se distanciado da política, ao mesmo tempo em que buscava junto a Oliveira Lima alternativas profissionais como colaborador na imprensa ou professor nos Estados Unidos. Seu relato da situação é eloquente: 
Passei agora uma semana trágica de 2 a 9 da corrente, com duas sangrentas revoluções em Lisboa e no Porto, e outros pequenos focos na Figueira Vila Real, Faro, etc. O governo, fracamente e imprevidentemente, deu azo a que se formasse a conjura, mas o exército esmagou-a, afogou-a em sangue. Umas centenas de mortos e feridos! Trago o espírito numa grande opressão. Durante essa semana não pude trabalhar, mal dormi até, aqui encerrado em casa, de janelas fechadas, a ouvir a fuzilaria duma verdadeira guerra civil. Lamentavelmente vi confirmar-se quanto tenho dito da incapacidade do governo, cuja [?] está longe da gravidade do mandato, que Ihe confiou o exército (Lisboa, 25/3/1927).

As represálias se estendiam até sua vida profissional, pois foi impedido de ingressar como docente na Universidade de Coimbra conforme a mesma carta: "Creio ter-Ihe dito que o meu decreto de nomeação para a cadeira de Metodologia das Ciências Filosóficas fora assinado pelo presidente, que assim me o comunicou. Pois não chegou a ser publicado e eu fiquei a pão e laranja". O impressionante é que naquelas circunstâncias, ele conseguisse pensar projetos intelectuais, produção e divulgação de obras. Era seu refúgio, como dizia:

Durante estes dias trágicos, em reação contra aquelas misérias, delineei uma obra nova: História de Portugal e sua influência na civilização universal (1128-1928), para comemorar o $8^{\circ}$ centenário da fundação da nacionalidade. Eu apenas dirijo e escrevo num capítulo. A obra, que já tem editor, compor-se-á de 3 vols: um sobre a história política e social da metrópole; outro sobre as navegações, conquistas e colonização; e outro sobre a cultura. Cada capítulo será redigido por um especialista. Para a sua pena tinha reservado o capítulo VIII do $2^{\circ}$ vol: O Brasil - sua colonização (1800-1822). Trata-se duma obra de síntese e de crítica. Poderia dar-lhe umas 80 páginas.

Diga-me duas palavras a respeito deste projeto. Só lamento a falta de colaboradores como o conde de Sabugosa, o Sardinha, Carlos França, Maximiano de Lemos, Luciano Pereira da Silva. O J. Lúcio Azevedo está falado: concorda e faz a evolução econômica.

Nomeado novamente para a direção da Biblioteca Nacional para fazer demissões no contexto de ascensão do autoritarismo, o direcionamento imposto por ele à reorganização de quadros levou a uma agressão feita por um funcionário em 3 de março de 1927. Em decorrência, o governo encerrou as oficinas gráficas da Biblioteca e demitiu os empregados desse serviço (CORREIA, 2002, p. 163).

Os pormenores do atentado podem serconhecidos por uma carta enviada por sua esposa Dulce a Flora de Oliveira Lima, relatando "sigilosamente" a situação e pedindo-Ihe que ajudasse a encontrar um trabalho que Ihes permitisse sair de Portugal. Até que ponto de comum acordo com o marido, não é possível saber, mas seguindo os protocolos, não se dirigiu diretamente a Oliveira Lima. Logo nova carta, desta vez do interessado, reforçava o pedido de socorro:

15 operários quiseram me matar, fechados a sós comigo no meu gabinete. Defendi-me como pude, com perfeito sangue-frio, graças a Deus, mas não pude evitar o ferimento profundo na testa. Saí no dia 20 para um banquete, q. me ofereceram os meus amigos, o que decorreu com grande brilho.

E como visse a cidade a favor dos bandidos e como o miserável Alfredo de Magalhães se bandeou com a C.G.T. e com a Seara Nova, demiti- 
me no dia 22. E cá estou de novo com os livros e com a família. Mas a decepção foi muito profunda. Não como, pouco durmo e preocupa-me a insegurança da minha vida, não por mim, mas pelos meus. [...] eu estou condenado à morte na primeira sarrafusca que rebente, o que não tardará. Eu sei as cartas e as informações, que recebo. Sinto-me com um pé no outro mundo [...].

Para conservar a vida e retemperar um pouco os nervos, queria ir fazer-Ihe uma visita. Para facilitar a minha saída, precisava de receber uma carta oficial do reitor da Universidade de Washington, a sua, ou outra corporação, convidando-me para ir aí dar conferências. Esse convite não envolvia o menor encargo com a minha viagem para a Universidade ou para a corporação que me convidará. Eu cá mobilizo um [...] para isso. Uma vez lá furarei a vida; se tiver algum resultado muito bem, se não, voltarei, após uns meses de esquecimento mais resignado à torpe capadócia.

Quer fazer-me o grande, o enorme favor de me conseguir esse convite, em papel timbrado, um selo branco, tudo que autentique? Desse modo o cônsul deixa-me embarcar prontamente, segundo me informou.

O meu conhecimento da história e literatura de Portugal e Espanha pode ser útil aí, onde há uma certa corrente de hispanofilia. É uma experiência. Quando muito perderei uns centos de dólar, mas ganho o enriquecimento espiritual da viagem. E trarei um livro sobre o espírito americano. E de lá escreverei para o Brasil e para a Espanha (Lisboa, 27 /3/1927).

Reconduzido, por pouco tempo ainda permaneceu no cargo na Biblioteca, onde exerceu papel "essencialmente político" de desbaratamento do núcleo político-cultural do republicanismo reunido na revista Seara Nova, que aglutinou escritores e intelectuais contrários ao salazarismo, entre eles Jaime Cortesão (CORREIA, 2002, p. 164-5).

Ao mesmo tempo, se envolvia cada vez mais em atividades políticas referidas na mesma carta: "Interrompi esta por terem chegado vários amigos. A minha casa é agora muito frequentada por elementos fortes, que dizem apreciar a minha energia e querem lançar-me em empreendimentos fortes, mas eu só quero fazer literatura" (Lisboa, 25/3/1927).

Não houve tempo para a concretização de novos projetos historiográficos com Oliveira Lima. Sua prisão de 82 dias, seguida de degredo em Luanda (Angola) fuga e exílio na Espanha, em 1927, após o fracasso da chamada Revolução dos Fi-Fis (Filomeno da Câmara e Fidelino), foi a primeira ruptura. Logo depois, em 1928, falecia Oliveira Lima.

Nos anos que se seguiram, Fidelino acabaria por vir residir no Brasil, onde criou a cadeira da Literatura Portuguesa na Faculdade de Filosofia da Universidade de São Paulo e lecionou de 1938 a 1948, realizando afinal seu projeto de tornar-se professor universitário e assim obter a incontestável consagração de sua obra.

\section{Referências bibliográficas}

AMORA, Antônio Soares. Fidelino de Figueiredo. In: PORTUGAL. BIBLIOTECA NACIONAL. Fidelino de Figueiredo 1888-1967. Lisboa: Biblioteca Nacional, 1989, p. 9-16.

BOURDIEU, P. Campo intelectual e projeto criador. In: POUILLON, Jean et al. (org.).

Problemas do estruturalismo. Rio de Janeiro: Zahar, 1968, p. 105-45. 
CARDOSO, Vicente Licínio. Um novo livro de Oliveira Lima. In:

Pensamentos americanos. Rio de Janeiro: Praça da Cruz Vermelha, 1937 , p. $183-190$.

Carta circular de adesão, s/d. assinada por Cristóvão Aires, Davi Lopes, José Leite de Vasconcelose Fidelino de Figueiredo.

CATROGA, Fernando. O Republicanismo como Projecto. In: REIS, António (coord.). A República ontem e hoje. Lisboa: Edições Colibri/Fundação Mário Soares/ Instituto de História Contemporânea da Universidade Nova de Lisboa, 2002, p. 33-39.

CHARTIER, Roger (dir.). La correspondance. Paris: Fayard, 1991.

CORREIA, Helder Manuel Bento. Fidelino de Figueiredo na cultura histórica e política do seu tempo (1889-1927). Dissertação (Mestrado) Faculdade de Letras, Universidade de Lisboa, Lisboa, 2002.

Estatutos da Sociedade Portuguesa de Estudos Históricos. Lisboa, Typ. da Cooperativa Militar, 1911.

FIGUEIREDO, Fidelino de. O espírito histórico. Lisboa: Typ. Da Cooperativa Militar, 1910.

. Estudos de Literatura, 1. série (1910-1916), Lisboa, 1917.

. Torre de Babel. Lisboa: Empresa Literária Fluminense, 1925.

LIMA, M. de O. Aspectos da história e da cultura no Brasil. Lisboa: Livr. Clássica Editora, 1923.

. Aspectos da literaturacolonial brasileira. Leipzig: F. A. Brockhaus, 1896.

Aspectos da literaturacolonial brasileira. Rio de Janeiro: INL/ Fundação Nacional Pró-memória, 1984.

D. João VI no Brasil. Rio de Janeiro: Typ. Do Jornal do Comércio, 1908.

D. João VI no Brasil. 3. ed. Rio de Janeiro: Topbooks, 1997.

. Dom Miguel no Trono. Imprensa da Universidade de Coimbra, 1933.

Dom Pedro e Dom Miguel. São Paulo: Melhoramentos, 1925.

. Memórias: estas minhas reminiscências. Recife: Sec. Turismo, Cultura

e Esportes, 1986.

O movimento da Independência (1821-1822). São Paulo, Weiszflog/Melhoramentos, 1922.

. Obra Seleta. Org. Barbosa Lima Sobrinho. Rio de Janeiro: MEC-INL, 1971.

Manifesto da Sociedade Portuguesa de Estudos Históricos. Lisboa, 01 de abril de 1912. 
MATTOSO, J. (dir.). História de Portugal: o liberalismo. Lisboa: Estampa, 1997. MIRANDA, J.C. Manoel de Oliveira Lima: o Curso Superior de Letras - o "Correio do Brasil". Ocidente, n. 345, p. 18-22, 1967.

- Manuel de Oliveira Lima. A passagem por Portugal em 1923 e a inauguração dos Estudos Brasileiros na Faculdade de Letras de Lisboa. Ocidente, n. 354, p. 107-112, 1967.

Projeto apresentado, em janeiro, a Sua Excia. o Ministro da Justiça. Lisboa: Sociedade Portuguesa de Estudos Históricos, 1912.

SIRINELLI, François, Os intelectuais. In: RÉMOND, René (org.). Por uma história política. 2. ed. Rio de Janeiro: FGV, 2003, p. 231-269. 